\title{
Research on New Intelligent Optimization Algorithm Based on the Law of Universal Gravitation
}

\author{
Zhong Ren, Qisong Qi*, Qing Dong and Gening Xu \\ School of Mechanical Engineering, Taiyuan University of Science and Technology, Taiyuan 030024, China
}

\begin{abstract}
In order to solve the problem of global optimization, a new optimization method based on the law of universal gravitation is proposed, which is a random search algorithm derived from the simulation of natural imagination, which belongs to the category of evolutionary computation and is a new intelligent optimization algorithm. This method abstracts the global optimal value into a "black hole" in the universe, and other free celestial bodies in the universe approach the "black hole" by gravitational force, and are eventually "swallowed" by the black hole. The direction and step of the algorithm iteration are deduced through the formula of gravitation, which reduces the influence of the stochastic factors on the algorithm and improves the efficiency of the optimization calculation. Through numerical experiments, it is proved that the performance of the algorithm in global convergence and computing speed is superior to other optimization algorithms in the relevant literatures, and the specular reflection algorithm is also proven to be an effective and reliable optimization tool when solving high-dimensional optimization problems. It is applied to the optimization design of crank and rocker mechanism, and the calculation result further affirms the value of the algorithm in the field of engineering calculation.
\end{abstract}

Keywords-global optimization; gravitation; numerical experiments; crank rocker

\section{INTRODUCTION}

The Intelligent optimization algorithm, also known as the modern heuristic algorithm, is a random search algorithm based on the biological intelligence or physical phenomena. The Intelligent optimization algorithm has the global optimization performance, the universality is strong and is suitable for the parallel processing. This algorithm generally has a rigorous theoretical basis, and not only by virtue of expert experience, theoretically can find the optimal solution, or approximate optimal solution in a certain time. The common characteristics of intelligent optimization algorithm are: from the arbitrary solution, according to a certain mechanism, a certain probability in the entire solution space to search for the optimal solution, because they can extend the search space to the entire problem space, thus has a global optimization performance. In recent decades, some of the classical mathematical programming principles are very different, trying to simulate the natural ecosystem mechanism to solve complex optimization problem of bionic Intelligent optimization algorithm has been put forward and a lot of improved research, this aspect of the content, such as simulated annealing algorithm[1], Genetic algorithm[2-3], Artificial neural network technology[4], Artificial immune algorithm[5] and swarm intelligence algorithm[6-8] and so on. These algorithms greatly enrich the modern optimization technology, but also provide a practical solution to the combinatorial optimization problems which traditional optimization techniques are difficult to deal with.

As an important branch of science, intelligent optimization algorithm has been highly valued by researchers and has been popularized and applied rapidly in many fields. Lu Deng[9] a sample optimization method based on the improved genetic algorithm is proposed to optimize the test cost to the optimal target, and a model for selecting and optimizing the Fault sample is established, which proves that the method can effectively reduce the cost of the test verification test. Sen Wang[10] based on the theory of genetic algorithm, the algorithm is improved by using chaos and whole annealing technique, the performance of the algorithm is improved, and the improved algorithm is applied to the optimal dispatching of the hydropower station, which provides a new effective way for the optimization of the large-scale hydropower system. Wenyuan $\mathrm{Fu}[11]$ for the low computational efficiency of traditional simulated annealing algorithms, by combining Brownian motion with simulated annealing, an intelligent heuristic algorithm is proposed, and the new algorithm is superior to the original algorithm in search speed, stability and computational efficiency. Wenfeng Zhu[12] the nonlinear mapping of sectional structure parameters and compressive loads is established by neural network, which realizes the parallel optimization of the parameters of the door sealing system. This method can significantly shorten the product development cycle; In view of the problem of insufficient searching ability of constrained boundary particles in boundary region, Jianlin Wang[13] proposes a co nstrained multi-objective particle swarm optimization algorithm based on adaptive Evolutionary learning, which proves that the proposed algorithm can obtain better convergence and The Pareto frontier of distribution and diversity; Pengzhen Du[14] an object-oriented multi-role ant colony algorithm is proposed and applied to the solution of TSP, and the role division of Ant Colony is carried out, the ant groups of different roles carry out different search strategies for the Relation of urban category, and enhance the searching ability of ant colony. The solution quality is improved greatly; In order to study the multi-objective optimization problem of hydrodynamic bearing, Qingbo LU[15] proposes an improved multi-objective difference evolutionary algorithm, puts forward the strategy of population construction, eliminates the disadvantage of decreasing the global search ability of the population caused 
by the same individual in the late evolutionary population, and improves the global optimization ability of the algorithm. The improved algorithm is proved to have better convergence speed and diversity by engineering example, and for the disadvantage of low searching efficiency, easy to fall into local optimal and low precision, Huiying Wang[16] proposed hybrid colony algorithm (Hybrid Bee colony). Combining the local convergence of artificial colony algorithm with the global convergence of simulated annealing algorithm, this paper provides a new mechanism for artificial colony algorithm.

All of these algorithms have significantly improved computational efficiency and ensured the application and penetration of intelligent optimization algorithms in various fields. However, the algorithms in the above-mentioned literature are improved on the basis of the original algorithm, and the improved algorithm still cannot completely get rid of the defects in some aspects of the original algorithm, so the researchers have been working to explore a new optimization method to simulate some natural phenomena. Tong $\operatorname{Li}[17]$ from the phototropism characteristics of the plant, the feasible domain of integer programming is used as the growth environment of the plant, which provides a new bionic global optimization algorithm for solving the problem of integer programming-simulating the plant growth algorithm; Wen-tsao Pan plays a new approach to optimization based on the foraging behavior of Drosophila- Drosophila algorithm (Fruit fly optimization algorithm, FOA), FOA has a very good group intelligence, application area[18] is particularly broad, in the neural network, support vector regression parameter optimization, financial management, enterprise risk and other aspects have important application value. In this paper, a new intelligent algorithm based on Gravitation is proposed, the law of gravitation is used as the theoretical basis of the algorithm, the concept of "black hole" is introduced into the universe, and the "black hole" is the root of the attraction of all things (the global optimal solution), and then simulates the optimization model of the celestial motion approaching to the black hole. By using 5 classical optimization test functions to analyze the efficiency of global optimization calculation, the new algorithm is applied to the optimization design of gear reducer to verify its engineering application value.

\section{AN INTELLigent Algorithm BASED ON GRAVITATION}

\section{A. Basic Concepts}

The law of Gravitation is Isaac Newton published in 1687 in The Mathematical Principles of Natural Philosophy, Newton's universal Law of universal gravitation is expressed as follows: Any two particles are attracted by the force in the direction of the heart line. The mass is proportional to the product of their mass in proportion to the square of their distance, independent of the chemical composition of the two objects and the physical state of their media, as shown in figure one is the law of gravitation, and the relationship between $F_{1}$ and $F_{2}$ in figure (1).

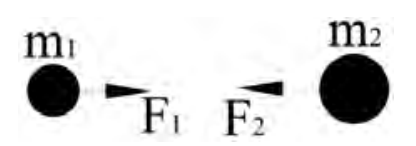

FIGURE I. LAW OF GRAVITATION

$$
F_{1}=F_{2}=\frac{G m_{1} m_{2}}{r^{2}}
$$

In the formula: $G$ is the gravitational constant, $m_{1}$ and $m_{2}$ are the mass of two objects respectively, and $r$ indicates the distance between the two objects.

In this paper, a new intelligent optimization algorithm based on the law of gravitation is proposed, which uses two objects of mass in space to attract each other, which is similar to the concept of "black hole" in astronomy, and defines the global optimal solution as "black hole" (mass is large enough), because of the existence of gravitation, other objects will approach it and eventually be " Swallowed." Since the mass of the "black hole" is large enough, it is possible to ignore the effect of other objects on gravity, assuming that all other objects are of equal quality. Using MATLAB as programming software, the new algorithm is summed up as the following necessary steps and program examples:

- The space is randomly determined by the "black Hole" attracted by the object $m$, of which $\operatorname{Indiv}_{i}\left(x_{i}^{1}, x_{i}^{2}, \mathrm{~L}, x_{i}^{n}\right), i=1,2, \mathrm{~L}, m$ is the dimension of the design space, $n$ randomly generated within the feasible region;

- Judging the gravity of each object in space and finding the object with the greatest gravitational force Best_Indiv;

$$
\text { Best_Indiv }\left(x_{\text {Best }}^{1}, x_{\text {Best }}^{2}, \mathrm{~L}, x_{\text {Best }}^{n}\right)=\min \left(g\left(\operatorname{Indiv}_{1}\right), g\left(\operatorname{Indiv}_{2}\right), \mathrm{L}, g\left(\operatorname{Indiv}_{m}\right)\right)
$$

In the formula: $g()$ is the function of gravitation judgment (Fitness functions);

- Due to the current inability to determine the position of the "black hole", according to the law of gravitation, the gravitational force is inversely proportional to the square of distance, so the current most gravitational object Best_Indiv $\left(x_{\text {Best }}^{1}, x_{\text {Best }}^{2}, \mathrm{~L}, x_{\text {Best }}^{n}\right)$ away from the "black hole" recently.

- To determine the approximate position of the "black Hole",

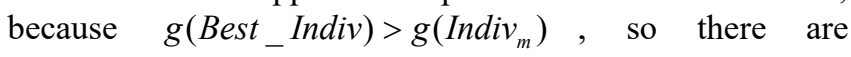
$\frac{G m m_{\text {Best }}}{r_{1}^{2}}>\frac{G m m_{\text {Indiv }}}{r_{2}^{2}}\left(m_{\text {Best }}=m_{\text {Indiv }}\right)$, so $r_{1}<r_{2}$, "black hole" position can be identified as two particles connected to the side of the perpendicular bisector near the object Best_Indiv, in order to simplify the calculation, the demarcation point $Q$ to the space of each axis projection, as shown in Figure 2, the shadow part is the object After the attraction can reach the area, when the dimension of the test space is 2 o'clock, the search area is a rectangle, when the test space dimension is 3 o'clock, the search area is the box shown in Figure 2, the figure of $\zeta$ is the coefficient, this article according to experience $1.0 \leq \zeta \leq 1.8$; 


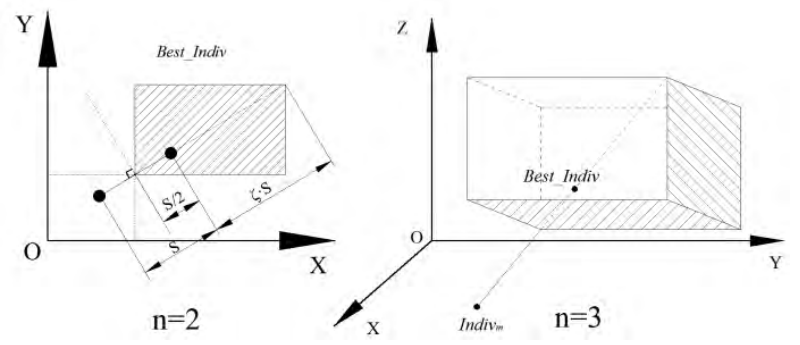

FIGURE II. SEARCH AREA WHEN 2-DIMENSIONAL OR 3-DIMENSIONAL SPACE

- $\quad$ Attracted by the "black Hole", other objects will approach it, such as Formula 3:

$$
\left.\begin{array}{l}
N_{-} w_{-} \operatorname{Indiv}_{i}\left(N_{-} w_{i}^{1}, N e w_{-} x_{i}^{2}, \mathrm{~L}, N e w_{-} x_{i}^{n}\right) \\
N e w_{-} x_{i}^{n}=x_{\text {Best }}^{n}+\left(\left(\zeta+\frac{1}{2}\right) * \text { rand }-\frac{1}{2}\right) *\left(x_{\text {best }}^{n}-x_{i}^{n}\right) \\
\operatorname{Indiv}_{i}\left(x_{i}^{1}, x_{i}^{2}, \mathrm{~L}, x_{i}^{n}\right)=N e w_{-} \operatorname{Indiv}_{i}\left(x_{i}^{1}, x_{i}^{2}, \mathrm{~L}, x_{i}^{n}\right)
\end{array}\right\}
$$

- Determine whether the gravity of the object is large enough, if not, then return to step 2, otherwise the output result.

\section{B. Best Design Parameters for the Algorithm}

The classical De Jong's function functions are used to analyze the algorithm, the performance of the algorithm is mainly from the following 4 aspects, 1) The best value of the coefficient $\xi$,2) The best individual population ( $m$ value); 3) limit of search space ( $a$ value) ; 4) design Dimension of space ( $n$ value). A comprehensive analysis of the effects of these 4 quantities on the optimization results, as shown in table 1, the data in tables $n=2$ and $n=3$ is the result of the algorithm iteration 100 times, when $n=30$, the number of iterations is 1000 , when 10000 :

$$
f\left(x_{1}, x_{2}, \mathrm{~L}, x_{n}\right)=\sum_{i=1}^{n} x_{i}^{2}\left(-a \leq x_{i} \leq a\right)
$$

\begin{tabular}{|c|c|c|c|c|c|c|c|c|c|c|c|c|c|}
\hline & $\mathrm{m}$ & 10 & & & 15 & & & 20 & & & 25 & & \\
\hline$n$ & $a$ & 10 & 100 & 1000 & 10 & 100 & 1000 & 10 & 100 & 1000 & 10 & 100 & 1000 \\
\hline \multirow{7}{*}{2} & $\begin{array}{l}1 . \\
0\end{array}$ & $\begin{array}{l}5.5296 \mathrm{E}- \\
18\end{array}$ & $\begin{array}{l}5.1349 \mathrm{E}- \\
12\end{array}$ & $\begin{array}{l}3.3483 \mathrm{E}- \\
23\end{array}$ & $\begin{array}{l}6.2476 \mathrm{E}- \\
44\end{array}$ & $\begin{array}{l}2.9722 \mathrm{E}- \\
55\end{array}$ & $\begin{array}{l}\text { 7.1871E- } \\
60\end{array}$ & $\begin{array}{l}3.6025 E- \\
71\end{array}$ & $\begin{array}{l}4.5474 \mathrm{E}- \\
66\end{array}$ & $\begin{array}{l}2.0960 \mathrm{E}- \\
66\end{array}$ & $\begin{array}{l}4.3420 \mathrm{E}- \\
73\end{array}$ & $\begin{array}{l}7.1930 \mathrm{E}- \\
69\end{array}$ & $\begin{array}{l}4.2910 \mathrm{E}- \\
68\end{array}$ \\
\hline & 1. & $\begin{array}{l}5.5038 \mathrm{E}- \\
27\end{array}$ & $7.1301 \mathrm{E}-$ & $\begin{array}{l}6.4601 \mathrm{E}- \\
40\end{array}$ & $1.0640 \mathrm{E}-$ & $9.0295 E-$ & $\begin{array}{l}2.5024 \mathrm{E}- \\
54\end{array}$ & $4.9409 \mathrm{E}-$ & $1.5547 \mathrm{E}-$ & $2.4981 \mathrm{E}-$ & $6.0986 \mathrm{E}-$ & $1.8871 \mathrm{E}-$ & $3.8696 \mathrm{E}-$ \\
\hline & 2 & 27 & $\begin{array}{l}32 \\
47220 F\end{array}$ & $\begin{array}{l}40 \\
104625\end{array}$ & 55 & 56 & & 66 & 62 & 61 & 64 & 61 & 61 \\
\hline & $\begin{array}{l}1 . \\
4\end{array}$ & $\begin{array}{l}1.4579 E- \\
43\end{array}$ & $\begin{array}{l}4.7220 \mathrm{E}- \\
41\end{array}$ & $\begin{array}{l}1.0462 E- \\
41\end{array}$ & $\begin{array}{l}1.9511 \mathrm{E}- \\
52\end{array}$ & $\begin{array}{l}3.7163 \mathrm{E}- \\
51\end{array}$ & $\begin{array}{l}1.1445 \mathrm{E}- \\
52\end{array}$ & $\begin{array}{l}1.0966 \mathrm{E}- \\
56\end{array}$ & $\begin{array}{l}1.3079 \mathrm{E}- \\
50\end{array}$ & $\begin{array}{l}5.0986 \mathrm{E}- \\
54\end{array}$ & $\begin{array}{l}4.4265 \mathrm{E}- \\
56\end{array}$ & $\begin{array}{l}2.9266 \mathrm{E}- \\
54\end{array}$ & $\begin{array}{l}3.4074 \mathrm{E}- \\
52\end{array}$ \\
\hline & 1. & $3.4075 \mathrm{E}-$ & $1.0429 \mathrm{E}-$ & $1.1254 \mathrm{E}-$ & $7.7288 \mathrm{E}-$ & $2.2049 \mathrm{E}-$ & $1.6019 \mathrm{E}-$ & $6.7955 \mathrm{E}-$ & $8.0078 \mathrm{E}-$ & $2.8344 \mathrm{E}-$ & $9.5029 \mathrm{E}-$ & $1.0530 \mathrm{E}-$ & $3.3125 \mathrm{E}-$ \\
\hline & 6 & & & & 44 & 38 & & & 48 & & & & \\
\hline & $\begin{array}{l}1 . \\
8\end{array}$ & $\begin{array}{l}8.7265 \mathrm{E}- \\
30\end{array}$ & $\begin{array}{l}1.9386 \mathrm{E}- \\
34\end{array}$ & $\begin{array}{l}2.1132 \mathrm{E}- \\
30\end{array}$ & $\begin{array}{l}8.5093 \mathrm{E}- \\
43\end{array}$ & $\begin{array}{l}4.5287 \mathrm{E}- \\
37\end{array}$ & $\begin{array}{l}2.7557 \mathrm{E}- \\
38\end{array}$ & $\begin{array}{l}4.5643 \mathrm{E}- \\
45\end{array}$ & $\begin{array}{l}3.0453 \mathrm{E}- \\
42\end{array}$ & $\begin{array}{l}3.4770 \mathrm{E}- \\
40\end{array}$ & $\begin{array}{l}7.1370 \mathrm{E}- \\
46\end{array}$ & $\begin{array}{l}1.8070 \mathrm{E}- \\
43\end{array}$ & $\begin{array}{l}1.7080 \mathrm{E}- \\
42\end{array}$ \\
\hline \multirow{6}{*}{3} & $\begin{array}{l}1 . \\
0\end{array}$ & 0.0110 & 0.1682 & $1.5340 \mathrm{E} 4$ & 0.0220 & $\begin{array}{l}8.0988 \mathrm{E}- \\
5\end{array}$ & 0.3233 & $\begin{array}{l}2.2082 \mathrm{E}- \\
5\end{array}$ & $\begin{array}{l}2.9899 \mathrm{E}- \\
9\end{array}$ & 0.0018 & $\begin{array}{l}6.0107 \mathrm{E}- \\
13\end{array}$ & $\begin{array}{l}4.3476 \mathrm{E}- \\
8\end{array}$ & $\begin{array}{l}4.0618 \mathrm{E}- \\
17\end{array}$ \\
\hline & $\begin{array}{l}1 . \\
2\end{array}$ & $\begin{array}{l}5.5209 \mathrm{E}- \\
4\end{array}$ & 0.1339 & 32.7534 & $\begin{array}{l}2.0599 \mathrm{E}- \\
10\end{array}$ & $\begin{array}{l}7.3392 \mathrm{E}- \\
5\end{array}$ & 0.0068 & $\begin{array}{l}3.8053 \mathrm{E}- \\
23\end{array}$ & $\begin{array}{l}7.0471 \mathrm{E}- \\
33\end{array}$ & $\begin{array}{l}\text { 6.1251E- } \\
39\end{array}$ & $\begin{array}{l}8.1288 \mathrm{E}- \\
21\end{array}$ & $\begin{array}{l}8.5560 \mathrm{E}- \\
46\end{array}$ & $\begin{array}{l}3.5155 E- \\
41\end{array}$ \\
\hline & $\begin{array}{l}1 . \\
4\end{array}$ & $\begin{array}{l}1.0762 \mathrm{E}- \\
13\end{array}$ & $\begin{array}{l}3.4430 \mathrm{E}- \\
4\end{array}$ & $\begin{array}{l}3.6225 \mathrm{E}- \\
12\end{array}$ & $\begin{array}{l}8.9666 E- \\
33\end{array}$ & $\begin{array}{l}8.5864 E- \\
36\end{array}$ & $\begin{array}{l}7.5089 \mathrm{E}- \\
23\end{array}$ & $\begin{array}{l}1.2953 E- \\
43\end{array}$ & $\begin{array}{l}1.5418 E- \\
38\end{array}$ & $\begin{array}{l}1.8384 \mathrm{E}- \\
38\end{array}$ & $\begin{array}{l}4.0319 \mathrm{E}- \\
41\end{array}$ & $\begin{array}{l}2.7175 \mathrm{E}- \\
41\end{array}$ & $\begin{array}{l}5.7256 \mathrm{E}- \\
38\end{array}$ \\
\hline & 1. & $1.3514 \mathrm{E}-$ & $5.9668 \mathrm{E}-$ & $9.7354 \mathrm{E}-$ & $2.3885 \mathrm{E}-$ & $4.8058 \mathrm{E}-$ & 4.3733E- & 7.2981E- & $7.7120 \mathrm{E}-$ & $7.6256 \mathrm{E}-$ & $1.4824 \mathrm{E}-$ & $1.3734 \mathrm{E}-$ & $3.0948 \mathrm{E}-$ \\
\hline & 6 & 15 & 9 & 18 & 32 & 32 & 25 & 35 & 32 & 32 & 35 & 34 & 33 \\
\hline & $\begin{array}{l}1 . \\
8\end{array}$ & $\begin{array}{l}3.6489 E- \\
27\end{array}$ & $\begin{array}{l}1.0213 E- \\
17\end{array}$ & $\begin{array}{l}2.6326 E- \\
20\end{array}$ & $\begin{array}{l}6.1411 \mathrm{E}- \\
27\end{array}$ & $\begin{array}{l}2.1050 \mathrm{E}- \\
26\end{array}$ & $\begin{array}{l}2.2540 \mathrm{E}- \\
20\end{array}$ & $\begin{array}{l}1.8061 \mathrm{E}- \\
31\end{array}$ & $\begin{array}{l}9.6725 \mathrm{E}- \\
26\end{array}$ & $\begin{array}{l}1.2500 \mathrm{E}- \\
25\end{array}$ & $\begin{array}{l}2.3992 \mathrm{E}- \\
34\end{array}$ & $\begin{array}{l}9.3720 \mathrm{E}- \\
29\end{array}$ & $\begin{array}{l}2.1856 \mathrm{E}- \\
27\end{array}$ \\
\hline \multirow{5}{*}{30} & $\begin{array}{l}1 . \\
0\end{array}$ & $4.6305 \mathrm{E} 2$ & $7.6310 \mathrm{E} 4$ & $9.3615 \mathrm{E} 6$ & 369.239 & $7.8905 \mathrm{E} 4$ & $9.3964 \mathrm{E} 6$ & $2.9247 \mathrm{E} 2$ & $7.9011 \mathrm{E} 4$ & $9.6054 \mathrm{E} 6$ & $4.7775 \mathrm{E} 2$ & $6.7439 \mathrm{E} 4$ & 9.6009E6 \\
\hline & $\begin{array}{l}1 . \\
2\end{array}$ & $\begin{array}{l}9.1606 \mathrm{E}- \\
9\end{array}$ & 1.4142 & $6.3128 \mathrm{E} 3$ & $\begin{array}{l}1.3898 \mathrm{E}- \\
9\end{array}$ & $\begin{array}{l}3.4990 \mathrm{E}- \\
9\end{array}$ & 3.4418 & $\begin{array}{l}1.7086 \mathrm{E}- \\
9\end{array}$ & $\begin{array}{l}2.4353 \mathrm{E}- \\
9\end{array}$ & 0.0019 & $\begin{array}{l}1.1839 \mathrm{E}- \\
9\end{array}$ & $\begin{array}{l}1.3934 \mathrm{E}- \\
9\end{array}$ & $\begin{array}{l}1.8180 \mathrm{E}- \\
9\end{array}$ \\
\hline & $\begin{array}{l}1 . \\
4\end{array}$ & $\begin{array}{l}1.4290 \mathrm{E}- \\
8\end{array}$ & $\begin{array}{l}0.1001 \mathrm{E}- \\
7\end{array}$ & 0.9986 & $\begin{array}{l}1.8671 \mathrm{E}- \\
9\end{array}$ & $\begin{array}{l}4.4830 \mathrm{E}- \\
9\end{array}$ & $\begin{array}{l}4.2163 \mathrm{E}- \\
9\end{array}$ & $\begin{array}{l}2.2630 \mathrm{E}- \\
9\end{array}$ & $\begin{array}{l}1.8823 \mathrm{E}- \\
9\end{array}$ & $\begin{array}{l}\text { 1.3932E- } \\
9\end{array}$ & $\begin{array}{l}1.3446 \mathrm{E}- \\
9\end{array}$ & $\begin{array}{l}1.4034 \mathrm{E}- \\
9\end{array}$ & $\begin{array}{l}2.0216 \mathrm{E}- \\
9\end{array}$ \\
\hline & $\begin{array}{l}1 . \\
6\end{array}$ & $\begin{array}{l}9.4489 \mathrm{E}- \\
9\end{array}$ & $\begin{array}{l}1.9526 E- \\
9\end{array}$ & $\begin{array}{l}7.2806 \mathrm{E}- \\
9\end{array}$ & $\begin{array}{l}5.2379 \mathrm{E}- \\
9\end{array}$ & $\begin{array}{l}3.2380 \mathrm{E}- \\
9\end{array}$ & $\begin{array}{l}3.6323 \mathrm{E}- \\
9\end{array}$ & $\begin{array}{l}2.9614 \mathrm{E}- \\
9\end{array}$ & $\begin{array}{l}1.2470 \mathrm{E}- \\
9\end{array}$ & $\begin{array}{l}1.5215 \mathrm{E}- \\
9\end{array}$ & $\begin{array}{l}2.0306 \mathrm{E}- \\
9\end{array}$ & $\begin{array}{l}1.2223 E- \\
9\end{array}$ & $\begin{array}{l}1.3622 \mathrm{E}- \\
9\end{array}$ \\
\hline & $\begin{array}{l}1 . \\
8\end{array}$ & $\begin{array}{l}5.3629 \mathrm{E}- \\
9\end{array}$ & $\begin{array}{l}1.1926 \mathrm{E}- \\
8\end{array}$ & $\begin{array}{l}2.5872 E- \\
9\end{array}$ & $\begin{array}{l}3.6120 \mathrm{E}- \\
9\end{array}$ & $\begin{array}{l}1.4837 \mathrm{E}- \\
9\end{array}$ & $\begin{array}{l}3.4108 E- \\
9\end{array}$ & $\begin{array}{l}1.4741 \mathrm{E}- \\
9\end{array}$ & $\begin{array}{l}1.6814 \mathrm{E}- \\
9\end{array}$ & $\begin{array}{l}1.7777 \mathrm{E}- \\
9\end{array}$ & $\begin{array}{l}9.5653 E- \\
10\end{array}$ & $\begin{array}{l}1.4143 \mathrm{E}- \\
9\end{array}$ & $\begin{array}{l}1.7833 E- \\
10\end{array}$ \\
\hline \multirow{7}{*}{$\begin{array}{l}10 \\
0\end{array}$} & $\begin{array}{l}1 . \\
0\end{array}$ & $2.1175 \mathrm{E} 3$ & $2.7681 \mathrm{E} 5$ & $2.7699 \mathrm{E} 7$ & $1.9326 \mathrm{E} 3$ & $3.0282 \mathrm{E} 5$ & $2.7544 \mathrm{E} 7$ & $1.8183 \mathrm{E} 3$ & $3.2749 \mathrm{E} 5$ & $3.0501 \mathrm{E} 7$ & $1.7765 \mathrm{E} 3$ & $2.8023 \mathrm{E} 5$ & $2.9850 \mathrm{E} 7$ \\
\hline & $\begin{array}{l}1 . \\
2\end{array}$ & $\begin{array}{l}6.6988 \mathrm{E}- \\
10\end{array}$ & $\begin{array}{l}6.9733 \mathrm{E}- \\
10\end{array}$ & 0.0052 & $\begin{array}{l}4.8388 \mathrm{E}- \\
10\end{array}$ & $\begin{array}{l}4.5340 \mathrm{E}- \\
10\end{array}$ & $\begin{array}{l}2.9658 \mathrm{E}- \\
10\end{array}$ & $\begin{array}{l}2.7765 \mathrm{E}- \\
10\end{array}$ & $\begin{array}{l}1.9620 \mathrm{E}- \\
10\end{array}$ & $\begin{array}{l}3.2810 \mathrm{E}- \\
10\end{array}$ & $\begin{array}{l}9.4596 E- \\
11\end{array}$ & $\begin{array}{l}1.5125 \mathrm{E}- \\
10\end{array}$ & $\begin{array}{l}1.3470 \mathrm{E}- \\
10\end{array}$ \\
\hline & 1. & $9.0630 \mathrm{E}-$ & $9.6635 \mathrm{E}-$ & $1.3667 \mathrm{E}-$ & 3.7470E- & $6.1473 \mathrm{E}-$ & 2.2072E- & $2.3056 \mathrm{E}-$ & $2.2941 \mathrm{E}-$ & $2.2283 \mathrm{E}-$ & $1.1335 \mathrm{E}-$ & $1.4361 \mathrm{E}-$ & $1.5984 \mathrm{E}-$ \\
\hline & 4 & 10 & 10 & 9 & 10 & 10 & 10 & 10 & 10 & 10 & 10 & 10 & 10 \\
\hline & 1. & $1.2315 \mathrm{E}-$ & $7.8757 \mathrm{E}-$ & $1.0008 E-$ & $5.4622 \mathrm{E}-$ & $4.6570 \mathrm{E}-$ & $4.5194 \mathrm{E}-$ & $1.8843 \mathrm{E}-$ & $2.8086 \mathrm{E}-$ & 1.9017E- & $1.1301 \mathrm{E}-$ & $1.1830 \mathrm{E}-$ & $1.4464 \mathrm{E}-$ \\
\hline & 6 & 9 & 10 & 9 & 10 & 10 & 10 & 10 & 10 & 10 & 10 & 10 & 10 \\
\hline & $\begin{array}{l}1 . \\
8\end{array}$ & $\begin{array}{l}9.0190 \mathrm{E}- \\
10\end{array}$ & $\begin{array}{l}6.2795 E- \\
10\end{array}$ & $\begin{array}{l}1.6553 \mathrm{E}- \\
9\end{array}$ & $\begin{array}{l}5.6480 \mathrm{E}- \\
10\end{array}$ & $\begin{array}{l}3.3886 E- \\
10\end{array}$ & $\begin{array}{l}4.5686 \mathrm{E}- \\
10\end{array}$ & $\begin{array}{l}1.5670 \mathrm{E}- \\
10\end{array}$ & $\begin{array}{l}2.3077 \mathrm{E}- \\
10\end{array}$ & $\begin{array}{l}2.8191 \mathrm{E}- \\
10\end{array}$ & $\begin{array}{l}1.1022 \mathrm{E}- \\
10\end{array}$ & $\begin{array}{l}9.9530 E- \\
11\end{array}$ & $\begin{array}{l}1.8693 \mathrm{E}- \\
10\end{array}$ \\
\hline
\end{tabular}

TABLE I. ANALYSIS OF DE JONG'S FUNCTION WITH THE NEW METHOD 
Tab 1 in the bold part of the data for the other three design parameters under the same conditions, $\xi$ to take different values of the optimal calculation results, Tab 2 is the impact of the optimal results of the probability statistics, from Tab 2, as the design space dimension from $n=2$ to $n=100$, the best value $\zeta$ is $\zeta=1.0, \zeta=1.4, \zeta=1.8, \zeta=1.8$. The change of the search space (parameter $\mathrm{m}$ ) and the number of population (parameter) has little effect on the design result, which proves that the algorithm searches in the global scope, and the calculation result of the algorithm will not change greatly because of the uncertainty of the initial state.

TABLE II. PROBABILITY AND STATISTICS OF OPTIMAL SOLUTION UNDER THE INFLUENCE OF THE VALUE OF $Z$

\begin{tabular}{llllll}
\hline \multirow{2}{*}{} & 1.0 & 1.2 & 1.4 & 1.6 & 1.8 \\
\hline 2 & $7 / 12$ & $2 / 12$ & $3 / 12$ & 0 & 0 \\
3 & 0 & $3 / 12$ & $5 / 12$ & $1 / 12$ & $3 / 12$ \\
30 & 0 & 0 & $1 / 12$ & $3 / 12$ & $8 / 12$ \\
100 & 0 & $3 / 12$ & $2 / 12$ & $2 / 12$ & $5 / 12$ \\
\hline
\end{tabular}

III NUMERICAL EXPERIMENTS AND ANALYSIS

\section{A. Test Function and Parameter Selection}

In order to verify the function optimization effect of the algorithm proposed in this paper, the optimization field is widely used in the simulation experiment of 4 classical datum functions[19], the dimension of the test function is 30 , the name of the test function, the mathematical expression, the convergence space and the global minimum are listed in Tab 3 respectively. The curve of 4 test functions in three-dimensional space is shown in Fig 3, wherein the test function Quadric, Rosenbrock and Quadric noise is a single-peak function, the global extremum is distributed in a flat and narrow valley, it is difficult to obtain its accurate calculation results. Test function Rastrigin is highly multimodal, the location of the minima is regularly distributed, which is used to test the global convergence of the algorithm.

TABLE III. THE SIX CLASSICAL TEST FUNCTION

\begin{tabular}{lllll}
\hline Name & Mathematical expressions & $\begin{array}{l}\text { Converge } \\
\text { nt domain }\end{array}$ & $\begin{array}{l}\text { Global } \\
\text { Extrem } \\
\mathrm{a}\end{array}$ & $\begin{array}{l}\text { Extremu } \\
\mathrm{m} \\
\text { coordinat } \\
\mathrm{es}\end{array}$ \\
\hline Quadric & $f_{1}(x)=\sum_{i=1}^{n}\left(\sum_{j=1}^{i} x_{j}\right)^{2}$ & {$[-100,100]$} & 0 & $(0,0, \mathrm{~L}, 0)$ \\
$\begin{array}{l}\text { Rosenbroc } \\
\mathrm{k}\end{array}$ & $f_{2}(x)=\sum_{i=1}^{n}\left[100\left(x_{i+1}-x_{i}^{2}\right)^{2}+\left(1-x_{i}^{2}\right)^{-}-[-10,10]\right.$ & 0 & $(1,1, \mathrm{~L}, 1)$ \\
$\begin{array}{l}\text { Quadric } \\
\text { Noise }\end{array}$ & $f_{3}(x)=\sum_{i=1}^{n} i \cdot x_{i}^{4}+\operatorname{random}[0,1]$ & {$[-1.28,1.28]$} & 0 & $(0,0, \mathrm{~L}, 0)$ \\
Rastrigin & $f_{5}(x)=\sum_{i=1}^{n}\left[x_{i}^{2}-10 \cdot \cos \left(2 \pi x_{i}\right)+10\right]$ & {$[-5.12,5.12]$} & 0 & $(0,0, \mathrm{~L}, 0)$ \\
\hline
\end{tabular}

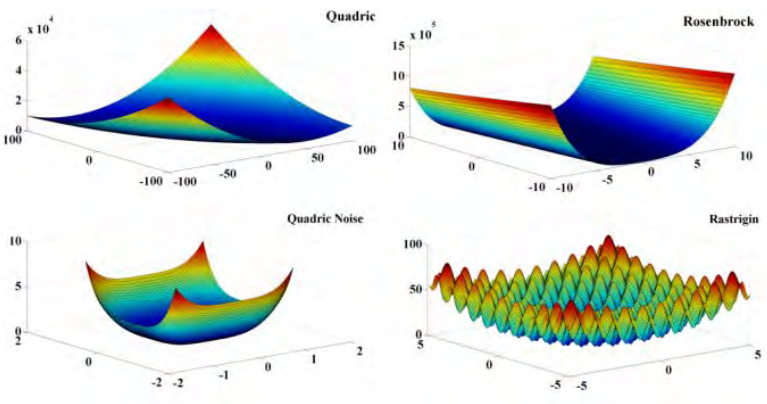

FIGURE III. THREE-DIMENSIONAL SPATIAL CURVE OF THE TEST FUNCTION

\section{B. Experimental Results Analysis}

In order to better test the optimization performance of this algorithm, the algorithm is compared with the improved particle swarm optimization algorithm (ASPSO[20]), which is more efficient than the present one, and the algorithm performs $30 \mathrm{i}$ ndependent operations on each test function, averaging as the optimization result, the parameter of the algorithm is set to $m=20$ : The best individual number in the population is $\zeta=1.8$; coefficient (Refer to Tab 2), the maximum number of iterations $\mathrm{n}=10000$. The test results of this algorithm are shown in Tab 4, as shown in Figure 4 as the adaptive value iteration curve of the test function.

\section{TABLE IV. COMPUTE RESULTS}

\begin{tabular}{lll}
\hline Test function & ASPSO $[20]$ & This algorithm \\
\hline Quardic & $2.68 \times 10^{-10}$ & $1.03 \times 10^{-12}$ \\
Rosenbrock & $1.9 \times 10^{-1}$ & $9.26 \times 10^{-3}$ \\
Quadric Noise & $6.14 \times 10^{-4}$ & $4.26 \times 10^{-3}$ \\
Rastrigin & $3.38 \times 10^{-14}$ & $6.22 \times 10^{-19}$ \\
\hline
\end{tabular}

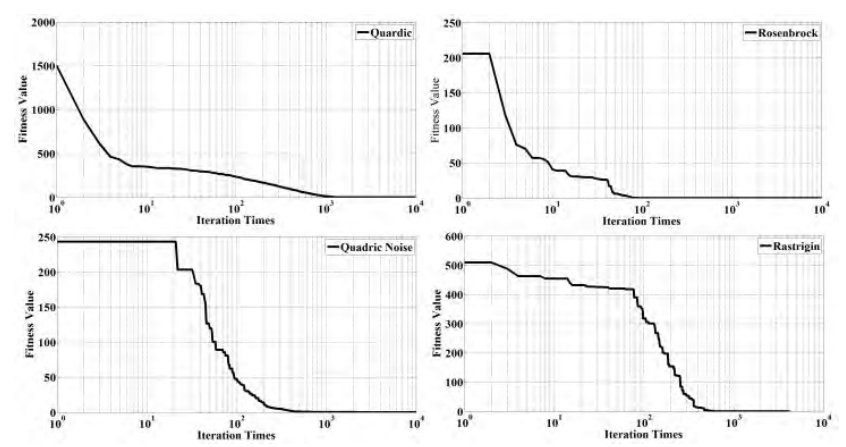

FIGURE IV. ITERATIVE CURVE OF OBJECTIVE FUNCTION

Analysis of the test results in Tab 4 shows that: compared with the improved particle swarm algorithm in the literature[20], this algorithm has a great improvement in the calculation accuracy, in addition to the test function quadric noise slightly lower, the accuracy of the other test functions have increased two orders of magnitude above, Especially the multi-peak function rastrigin, the accuracy of this algorithm improves the $5.4 \times 10^{4}$. Therefore, it is an effective optimization method to use this algorithm to improve the accuracy of the computation significantly. 


\section{ENGINEERING CASE ANALYSIS}

A general-purpose bridge crane box-type metal structure optimization model is used widely in the literature[21 23]. The mathematical representation of the optimization model is as follows, and the objective function $\mathrm{g}(\mathrm{x})$ is the weight of the unit length of the box girder. The optimal number of individuals in the population was $m=20$, the coefficient was $\zeta=1.8$ (reference to Tab 2), and the maximum number of iterations was $n=10000$. The program runs independently 100 times, and the optimal and average calculation results of 100 runs are listed in Tab 5, and several solutions of other literatures are listed in table 5 for easy comparison.

$$
\begin{gathered}
\min F(x)=x_{1} x_{3}+x_{2} x_{4} \\
\text { s.t. }\left\{\begin{array}{l}
0.75 L\left[\frac{P_{1}+7.8 \times 10^{-5}\left(x_{1} x_{3}+x_{2} x_{4}\right) L}{3 x_{1} x_{2} x_{4}+x_{1}^{2} x_{3}}+\frac{P_{2}}{3 x_{1} x_{2} x_{3}+x_{1}^{2} x_{4}}\right]-140 \leq 0 \\
\frac{P_{1} L^{3}}{1.68 \times 10^{6}\left(3 x_{1}^{2} x_{2} x_{4}+x_{1}^{3} x_{3}\right)}-\frac{L}{700} \leq 0 \\
\frac{x_{2}}{x_{4}}-60 \leq 0, \frac{x_{1}}{x_{3}}-160 \leq 0
\end{array}\right.
\end{gathered}
$$

In the formula: $1=10500, \mathrm{p} 1=120000, \mathrm{p} 2=12000$;

$X_{1}, X_{2}, X_{3}$ and $X_{4}$ are the sectional dimensions of the main girder of the crane box type, wherein the $700 \leq X_{1}$ $\leq 800,350 \leq X_{2} \leq 400,5 \leq X_{3} \leq 10,5 \leq X_{4} \leq 10$.

Compared with the data in Tab 5, we can solve the practical engineering structure optimization problem by using the new algorithm, and the calculation result of this algorithm is better than[21-23], which proves that the algorithm has better global searching ability, and this algorithm is a new optimization method which is worth popularizing widely. has a wide range of engineering application prospects.

\section{TABLE V. OPTIMIZATION RESULTS AND COMPARISON OF}

\begin{tabular}{|c|c|c|c|c|c|}
\hline \multirow[b]{2}{*}{ Project } & \multicolumn{2}{|c|}{ This algorithm } & \multirow[b]{2}{*}{$\begin{array}{l}\text { Genetic-neural } \\
\text { network[21] }\end{array}$} & \multirow{2}{*}{$\begin{array}{l}\text { Chaotic } \\
\text { genetic } \\
\text { algorithm[22] }\end{array}$} & \multirow{2}{*}{$\begin{array}{l}\text { Differential } \\
\text { evolution } \\
\text { algorithm[23] }\end{array}$} \\
\hline & $\begin{array}{l}\text { Best } \\
\text { results }\end{array}$ & Average & & & \\
\hline$F(x)$ & 5877.529 & 5884.539 & 6113.396 & 6071.6127 & 5903.3093 \\
\hline$X_{1}$ & 738.945 & 734.069 & 791.968 & 799.0784 & 772.3285 \\
\hline$X_{2}$ & 359.104 & 361.814 & 320.440 & 350.2652 & 350.0 \\
\hline$X_{3}$ & 5.002 & 5.001 & 5.000 & 5.0210 & 5.0 \\
\hline$X_{4}$ & 6.075 & 6.118 & 6.627 & 5.8796 & 5.833 \\
\hline
\end{tabular}
ENGINEERING EXAMPLES

\section{CONCLUSION}

In this paper, a new intelligent optimization algorithm based on the law of universal gravitation is proposed to solve the global optimization problem, in which the target function and the coordinate information of the design variable are used to determine the direction and step of the search in simulating the process of "black hole" engulfing other celestial bodies in the universe. This algorithm is a general intelligent optimization algorithm, which has no excessive requirements for the mathematical model, and is suitable for solving large-scale and multi-peak optimization design problems. Using 4 classical datum functions to simulate the performance of the algorithm, the test results show the high precision of the algorithm, especially the advantages in solving the multi-peak function. The new algorithm is applied to the optimization design of the actual engineering structure, and the comparison and analysis of the data results existing with other algorithms proves that the algorithm has good ability to solve the practical problems.

\section{REFERENCES}

[1] S. Kirkpatrick, C. D. Gelatt, M. P. Optimization by Simulated Annealing Science 1983; 220(4598): 671-680.

[2] Giulio Lorenzini, Cesare Biserni, Emanuel da Silva Diaz Estrada, et al. Genetic algorithm applied to geometric optimization of isothermal Y-shaped cavities. Journal of Electronic packing 2014; 136.

[3] Daniel A. McAdams, Wei Li. A novel method to design and optimize flat-foldable origami structures through a genetic algorithm. Journal of Computing and Information Science and Engineering 2014; 14.

[4] Na Y, Yan Z. Finite element model updating of tibetan structure based on artificial neural network. Journal of vibration and shock 2013; 32(9): 125-129.

[5] Yutao Q, Fang L and Licheng J. A distributed artificial immune algorithm for numerical optimization. Acta Electronica Sinica 2013; 37(7): 1554-1561.

[6] Lixin N, Tianxia Z and Bo Z. Dual kernel support vector machine optimized by particle swarm optimization algorithm and its application. Journal of Vibration, Measurement \& Diagnosis 2014; 34(3): 565-569.

[7] Guangyu L, Chen G and Yanxin L. Fractional-order control of USV course based on improved PSO alg orithm. Systems Engineering and Electronics 2014; 36(6): 1146-1151.

[8] Zhaohong J, Dan L and Longpeng L. Improved ant colony algorithm for solving batch scheduling problem with non-identical sizes. Control and Decision 2014; 29(10): 1758-1764.

[9] Deng L, Aiqiang X and Zhongde Wu. Method of failure sample optimization selection based on genetic algorithm. Syst Eng Electron 2014; 36: 1-7.

[10] Sen W, Chuntian C, Xinyu W, et al. Application of self-adaptive chaos whole annealing genetic algorithm to optimal operation of hydropower station groups. Journal of Hydroelectric Engineering 2014; 33(5): 63-71.

[11] Wenyuan F and Chaodong L. Brownian motion based simulated annealing algorithm. Chinese Journal of Computers 2014; 37(6): 1301-1308.

[12] Wenfeng Z, Jie W, Guoyong Xia, et al. Optimization method of automotive door sealing system with bar structure based on neural networks. Journal of Shanghai Jiaotong University 2014; 48(3): 377-381.

[13] Jianlin W, Jiahuan W, Chaoran Z, et al. Constrained multi-objective particle swarm optimization algorithm based on self-adaptive evolutionary learning. Control and Decision 2014; 29(10): 1765-1770.

[14] Pengzhen D, Zhenmin T and Yan S. An object-oriented multi-role ant colony optimization algorithm for solving TSP problem. Control and Decision 2014; 29(10): 1729-1736.

[15] Qingbo Lu, Xueliang Z, Jiaohua W, et al. Multi-objective optimization of hydrodynamic sliding bearing based on di fferential evolution algorithm. Transaction of the Chinese Society for Agriculture Machinery 2013; 44(3): 230-236, 245.

[16] Huiying W and Wenbin W. Hybrid bee colony algorithm with modified search strategy. Systems Engineering and Electronics 2014; 36(10): 2094-2101.

[17] Tong L, Chenfeng W, Wenbo W, et al. A global optimization bionics algorithm for solving inter programming-plant growth simulation algorithm. System Engineering - Theory \& Practice 2005; 25(1): 76-85.

[18] Wen-Tsao Pan. A new Fruit Fly Optimization Algorithm: Taking the financial distress model as an example. Knowledge-Based Systems 2012; 
26: 69-74

[19] JANEZ B, SASO G and BOBKO B. Self-adapting control parameters in differential evolution: a co mparative study on numerical benchmark problems. IEEE Transactions on Evolutionary Computation 2006; 12(10): 646-657.

[20] Xiang L and Min H. Particle swarm optimization for adaptive selection model based on velocity diversity. Computer Engineering and Design 2014; 35(8): 2907-2911.

[21] Zhengjia Z, Hongzhong $\mathrm{H}$ an d Xin C. A genetic-neural network algorithm in optimum design. Journal of Southwest Jiaotong University 2000; 35(1): 67-70.

[22] Huixin G, Xiaoyi C and Weiyue X. Chaos-genetic optimal algorithm and application in mechanical optimal design. Journal of Machine Design 2003; 20(10): 23-25.

[23] Qingbo L, Xueliang Z, Jiaohua W, et al. Modified differential evolution and its application. Transactions of the Chinese Society for Agricultural Machinery 2010; 41(2): 193-197. 